\title{
Aspectos da poluição atmostérica: análise da qualidade do ar em Coronel Fabriciano e Timóteo, MG, Brasil
}

Marluce Teixeira Andrade Queiroz marluce.queiroz@bol.com.br

Centro Universitário do Leste de Minas Gerais (Unileste), Coronel Fabriciano, MG, Brasil

Beatriz Luz Carvalho Correio beatrizluzcarvalho@hotmail.com Centro Universitário do Leste de Minas Gerais (Unileste). Brasil

Jordânia Alexina do Carmo Cardeal Correio

jordaniacardeal@hotmail.com Centro Universitário do Leste de Minas Gerais (Unileste). Brasil

Tayla Luiza Pereira Borges Correio

taylaluiza_pereiraborges@yahoo.com.br Centro Universitário do Leste de Mina Gerais (Unileste). Brasil

\author{
RESUMO
}

Os processos industriais, os veículos automotores e as queimadas são, dentre as atividades antrópicas, as maiores causas da introdução de poluentes à atmosfera. Essas substâncias podem apresentar efeitos nocivos à saúde humana, ainda sendo capazes de ocasionar danos à flora, faunas e aos materiais, sendo assim, a investigação dos teores desses compostos químicos dispersos no ar reveste-se de elevada importância socioambiental. Nesse estudo são apresentadas informações sobre a siderurgia, poluentes gerados e efeitos sobre a qualidade do ar na região do Vale do Aço, especificamente nas cidades de Coronel Fabriciano e Timóteo, Minas Gerais, Brasil. Os achados são dados secundários provenientes do monitoramento realizado pela Aperam South America e sendo comparados aos padrões legais estabelecidos no CONAMA 491/2018 que são rigorosamente atendidos pelo empreendimento. Entretanto, constataram-se valores elevados dos teores de Partículas Totais em Suspensão (PTS) e Partículas Inaláveis (PI) caracterizando-se a qualidade do ar como regular em alguns períodos notadamente na estação seca. Além disso, reforça-se que diversos estudos mostram que ainda em concentrações inferiores aos limites legais existe a probabilidade de efeitos deletérios para a população exposta ao ar contaminado. Desse modo, pontua-se quanto à necessidade do desenvolvimento de ações mais efetivas para mitigação dos transtornos ambientais.

PALAVRAS-CHAVE: Siderurgia. Qualidade do Ar. Medidas Mitigadoras. 


\section{INTRODUÇ̃̃O}

Krecl et al. (2019) pontuam que a qualidade do ar urbano é determinada por um complexo sistema de fontes fixas e móveis, sendo um sério problema para a população que vem se agravando nos países desenvolvidos e em desenvolvimento, tornando-se um dos maiores desafios para a gestão das cidades.

Na perspectiva da melhor compreensão desse transtorno ambiental inserese o fato de que a poluição do ar está associada a grandes aumentos dos sintomas clínicos, internações hospitalares, dos índices de freqüência/gravidade das morbidades e incluindo óbitos (PAIVA et al., 2014).

Esse panorama implica em um largo aumento das despesas médicas, sendo estimada como a causa de 800.000 mortes prematuras anuais em todo o mundo (WHO, 2002). Reforça-se, reconhecer os compostos químicos associados à poluição do ar, monitorar, quantificar e identificar os métodos de redução da emissão de poluentes atmosféricos será útil para as áreas da medicina, indústria, bem como para as decisões políticas e cidadãos no geral (SILVEIRA et al., 2014).

O incremento na degradação da qualidade do ar está relacionado diretamente com as indústrias atingindo áreas distantes e extensas. Exemplificando, as emissões atmosféricas geradas pela indústria chinesa, e deslocada pelo vento, está associada a mais de 3.100 mortes prematuras por ano na Europa Ocidental e nos Estados Unidos da América (EUA), de acordo com os estudos divulgados por World Health Organization (WHO, 2002).

Outro problema, segundo Pattinson et al. (2018), o crescente número de veículos em circulação, que se caracterizam como uma fonte móvel vem aumentando consideravelmente nas principais regiões urbanas durante as últimas décadas.

O número elevado de automóveis provoca a diminuição do tempo médio de percurso, entretanto, acarreta incremento da emissão de gases tóxicos, implicando em deterioração da qualidade do ar (DREHMER et al., 2015).

Ocorrem no motor daqueles veículos reações químicas associadas ao processo de combustão, e, através do tubo de escapamento são emitidas substâncias nocivas, tais como: monóxido de carbono, hidrocarbonetos, óxidos de nitrogênio, óxidos de enxofre, ácidos orgânicos e material particulado. Este último, devido ao seu tamanho microscópico, às suas propriedades químicas, e à sua persistência na atmosfera, pode se constituir em riscos graves à saúde pública, que variam desde irritação nos olhos a problemas respiratórios, causando custos diretos e indiretos para a sociedade em escala crescente (CABRAL et al., 2001).

Trata-se de uma questão com temática desafiadora principalmente em face da crescente demanda relacionada com a proteção da qualidade do ar.

Nakagawa et al (2010) alertam quanto à relevância do diagnóstico dos fatores que afetam esse compartimento ambiental, bem como a prevenção dos impactos futuros decorrentes de determinados eventos ou condições específicas, para melhor auxiliar a administração dos recursos atmosféricos com ações concretas e eficientes. 
A proposta desse estudo se direciona para análise da qualidade do ar em municípios que pertencem à Região Metropolitana do Vale do Aço (RMVA), sendo Coronel Fabriciano e Timóteo, Minas Gerais, Brasil.

Foram utilizados dados secundários provenientes da rede automática de monitoramento da qualidade do ar e meteorologia da Aperam Inox América do Sul S.A - RAMQAM APERAM Inox (APERAM).

Reforça-se que os dados são disponibilizados para consulta pública constituindo-se em importante meio de acesso aos resultados relativos à dispersão e concentração de poluentes provenientes dessa fonte estacionária. Entretanto, para melhor compreensão do risco ambiental exigem análise descritiva quali-quantitativa.

Pretende-se evidenciar que a existência da siderúrgica afeta diretamente a qualidade do ar com repercussões ao incremento de partículas inaláveis que podem contribuir para o adoecimento da população exigindo a adoção de medidas mitigadoras.

Entretanto, a existência de fontes difusas, notadamente o trânsito urbano, sugere que a siderurgia não pode ser apontada como a única responsável pelo decréscimo do status ambiental proporcionado pela presença de substâncias químicas inseridas na composição da atmosfera na região.

Desse modo, a adoção de políticas públicas visando à melhoria da qualidade do ar deve contemplar ações contínuas de monitoramento e requer a efetivação de medidas específicas para que sejam minimizados os efeitos adversos produzidos pela poluição veicular e das indústrias.

\section{REVISÃO DA LITERATURA}

\section{POLUIÇÃO DO AR}

A atmosfera é dividida em algumas camadas - troposfera, estratosfera, mesosfera, termosfera e exosfera - tendo como base as características físicoquímicas (Figura 1). Destas, as mais significantes são a troposfera, que se estende a partir da superfície terrestre até uma altitude de, aproximadamente, $11 \mathrm{~km}$, seguida da estratosfera, até, aproximadamente, $50 \mathrm{~km}$.

A temperatura da troposfera varia de uma média de 15으, ao nível do mar, a uma média de $-56^{\circ} \mathrm{C}$, no limite superior. A temperatura média da estratosfera, por sua vez, aumenta de $-56 \circ \mathrm{C}$, no limite com a troposfera, até - $2{ }^{\circ} \mathrm{C}$ na fronteira superior. A razão deste aumento é a absorção da energia solar ultravioleta pelo ozônio na estratosfera (MANAHAN, 2000).

A troposfera é a camada delgada de ar, relativamente denso, mais próximo à superfície da terra, que contém o ar que todos os seres vivos necessitam para respirar. A estratosfera é a camada protetora, que ajuda a absorver e dispersar a energia solar (CETESB, 2019). 
Figura 1 - Distribuição das camadas atmosféricas

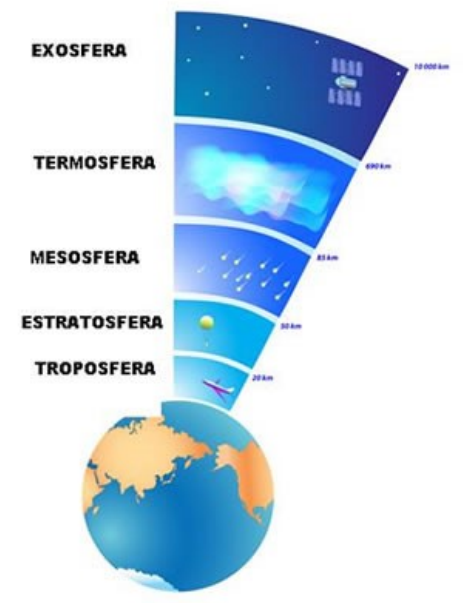

Fonte: Mundo da Educação (2020).

Encontra-se na troposfera em fase gasosa o ar atmosférico utilizado para a manutenção da vida no planeta Terra. A poluição do ar tem sido, desde a primeira metade do século $\mathrm{XX}$, um grave problema nos centros urbanos industrializados, com a presença cada vez maior dos automóveis, que vieram a somar com as indústrias, como fontes poluidoras (FEEMA, 2004, FEEMA, 2008).

Existem diferentes opiniões dos cientistas sobre o que constitui impureza ou a poluição da atmosfera. Para alguns, a contaminação supõe o aumento, ou, às vezes, a redução de certos componentes da atmosfera, que não existiria sem a atividade humana. Todavia, uma definição desta natureza seria um pouco limitada, uma vez que a atmosfera do planeta tem sofrido profundas mudanças em sua constituição ao longo dos tempos. Os fenômenos naturais, como erupções vulcânicas, incêndios florestais e tormentas de areia, decomposição de plantas e de animais, incluindo os aerossóis emitidos pelos oceanos, têm provocado significativas alterações locais, regionais e mesmo continentais, evidenciadas nos valores dos componentes atmosféricos. Os seres humanos têm vivido no planeta Terra durante milhares de anos e suas numerosas atividades influenciaram a composição do ar, antes mesmo que fosse possível medir seus elementos constitutivos. $\mathrm{O}$ ar é uma mistura complexa de muitas substâncias. Sem dúvida, quando se fala de contaminação do ar, os contaminantes são aqueles gerados pelas atividades do homem (antropogênicas). Pode-se considerar como contaminante a substância que produz um efeito prejudicial no ambiente. Estes efeitos podem alterar tanto a saúde, como o bem-estar das pessoas (FEEMA, 2008). Almeida et al. (2019) partiram do conhecimento de que a composição aproximada da atmosfera terrestre seria de $76 \%$ de nitrogênio e $23 \%$ de oxigênio. Os restantes $1 \%$ estariam distribuídos entre o vapor d'água, gases nobres, dióxido de carbono, hidrogênio, aerossóis e outros gases-traço, tudo distribuído numa altura, aproximada, de $100 \mathrm{~km}$.

Assim sendo, utilizaram o termo atmosfera não poluída, tomando essa composição e supondo a não interferência humana nesse equilíbrio. Compreende-se que o estado higrométrico do ar e a existência de indústrias poluidoras e de grande número de veículos trafegando em uma cidade alterem os valores indicados nas áreas industriais e centros urbanos densamente 
povoados. A simples presença do homem em um ambiente altera a taxa dos componentes (MACINTYRE, 1988). Entretanto, atualmente são utilizados padrões de qualidade do ar estabelecidos em conformidade com as diretrizes da Organização Mundial de Saúde (OMS). Esses indicadores variam de acordo com a abordagem adotada para balancear riscos à saúde, viabilidade técnica, considerações econômicas e várias outras condições interferentes relacionadas aos fatores políticos e sociais, que por sua vez dependem, entre outras coisas, do nível de desenvolvimento e da capacidade nacional de gerenciar a qualidade do $\operatorname{ar}$ (WHO, 2002).

As diretrizes recomendadas pela OMS levam em conta esta heterogeneidade e, em particular, reconhecem que, ao formularem políticas de qualidade do ar, os governos devem considerar cuidadosamente suas circunstâncias locais antes de adotarem os valores propostos como padrões nacionais (WHO, 2002).

\section{PRODUÇÃO DO AÇO E QUALIDADE DO AR}

A fronteira entre o ferro e o aço foi definida na revolução industrial, com a invenção de fornos que permitiam não só corrigir as impurezas do ferro, como adicionar-Ihes propriedades como resistência ao desgaste, ao impacto, à corrosão, etc. Por causa dessas propriedades e do seu baixo custo o aço passou a representar cerca de $90 \%$ de todos os metais consumidos pela civilização industrial (LEANDRO, 2007).

Basicamente, o aço é uma liga de ferro e carbono. O ferro é encontrado em toda crosta terrestre, fortemente associado ao oxigênio e à sílica. O minério de ferro é um óxido de ferro, misturado com areia fina. O carbono é também relativamente abundante na natureza e pode ser encontrado em diversas formas. $\mathrm{Na}$ siderurgia, usa-se carvão mineral, e em alguns casos, o carvão vegetal (LEANDRO, 2007).

O carvão exerce duplo papel na fabricação do aço. Como combustível, permite alcançar altas temperaturas (cerca de 1.500 Celsius) necessárias à fusão do minério. Como redutor, associa-se ao oxigênio que se desprende do minério com a alta temperatura, deixando livre o ferro. O processo de remoção do oxigênio do ferro para ligar-se ao carbono chama-se redução e ocorre dentro de um equipamento chamado alto forno. Antes de serem levados ao alto forno, o minério e o carvão são previamente preparados para melhoria do rendimento e economia do processo. O minério é transformado em pelotas e o carvão é destilado, para obtenção do coque, dele se obtendo ainda substâncias carboquímicas (LEANDRO et al., 2007).

No processo de redução, o ferro se liquefaz e é chamado de ferro gusa ou ferro de primeira fusão. Impurezas como calcário, sílica etc. formam a escória, que é matéria-prima para a fabricação de cimento (LEANDRO et al., 2007).

A etapa seguinte do processo é o refino. O ferro gusa é levado para a aciaria, ainda em estado líquido, para ser transformado em aço, mediante queima de impurezas e adições. O refino do aço se faz em fornos a oxigênio ou elétricos (SPAGNOL et al., 2015). 
Finalmente, a terceira fase clássica do processo de fabricação do aço é a laminação. $\mathrm{O}$ aço, em processo de solidificação, é deformado mecanicamente e transformado em produtos siderúrgicos utilizados pela indústria de transformação, como chapas grossas e finas, bobinas, vergalhões, arames, perfilados, barras etc. (SPAGNOL et al., 2015).

Entretanto, também existem aspectos contraproducentes relacionados com os resíduos, sejam emissões sólidas, líquidas ou gasosas. As fugacidades do material particulado presente nas emissões atmosféricas dessa indústria afetam a população que se encontra em regiões próximas. Pontua-se, ao modificar a composição do ar nas adjacências do empreendimento, conseqüentemente prejudicam o sistema respiratório da população, portanto, existe a necessidade de controlar esse tipo de problema visando o bem-estar social (FONSECA, 2011).

\section{EMISSÕES ATMOSFÉRICAS DA SIDERURGIA}

O quadro 1 a seguir contém informações sobre os tipos poluentes e composição química produzidos em grandes quantidades pela indústria siderúrgica, incluindo-se aí oxidantes fotoquímicos relacionados com a mistura de poluentes secundários formados pelas reações entre os óxidos de nitrogênio e compostos orgânicos voláteis, na presença de luz solar, sendo estes últimos liberados na queima incompleta e evaporação de combustíveis e solventes.

Quadro 1 - Poluentes atmosféricos emitidos no processo siderúrgico

\begin{tabular}{|c|c|}
\hline Tipo de Poluente & Composição Química \\
\hline Aerodispersóides & Poeiras, fumos, fumaça, névoa \\
\hline Compostos de enxofre & $\mathrm{SO}_{2}, \mathrm{SO}_{3}, \mathrm{H}_{2} \mathrm{~S}$, sulfatos \\
\hline Compostos de nitrogênio & $\mathrm{NO}, \mathrm{NO}_{2}, \mathrm{NO}_{\mathrm{x}}, \mathrm{HNO}_{3}, \mathrm{NH}_{3}$, nitratos \\
\hline Compostos orgânicos & $\begin{array}{c}\text { HC, aldeídos, partículas orgânicas, ácidos orgânicos, } \\
\text { nitratos orgânicos }\end{array}$ \\
\hline $\begin{array}{l}\text { Gases e vapores } \\
\text { inorgânicos }\end{array}$ & $\begin{array}{c}\mathrm{CO}, \mathrm{CO}_{2}, \mathrm{SO}_{2}, \mathrm{O}_{3}, \mathrm{HC}, \mathrm{NH}_{3}, \mathrm{Cl}_{2}, \mathrm{H}_{2} \mathrm{~S} \text {, névoas ácidas, névoas } \\
\text { alcalinas }\end{array}$ \\
\hline
\end{tabular}

Fonte: MMA, Adaptado (2020).

As emissões atmosféricas mais importantes provenientes das unidades operacionais da indústria siderúrgica são: material particulado (MP), óxidos de nitrogênio ( $\left.N O, \mathrm{NO}_{2}\right)$, óxidos de enxofre $\left(\mathrm{SO}_{2}, \mathrm{SO}_{3}\right)$, óxidos de carbono $\left(\mathrm{CO}, \mathrm{CO}_{2}\right)$, metais pesados, compostos orgânicos voláteis, compostos acíclicos aromáticos, dioxinas e furanos, entre outros (ALMEIDA, 1999).

O principal produto desta reação é o ozônio, por isso mesmo utilizado como parâmetro indicador da presença de oxidantes fotoquímicos na atmosfera. Tais poluentes formam a chamada névoa fotoquímica ou "smog fotoquímico", que possui este nome porque causa na atmosfera diminuição da visibilidade. Além de prejuízos à saúde, o ozônio pode causar danos à vegetação. É sempre bom ressaltar que o ozônio encontrado na faixa de ar próxima do solo, onde respiramos chamado de é tóxico. Entretanto, na estratosfera (a cerca de $25 \mathrm{~km}$ de altitude) o ozônio tem a importante função de proteger a Terra, como um filtro, dos raios ultravioletas emitidos pelo Sol (ASSUNÇÃO, 1998). 


\section{PADRÕES DE QUALIDADE DO AR NO BRASIL}

No Brasil os padrões de qualidade do ar são estabelecidos pela Resolução CONAMA no 491/2018, que revogou e substituiu a Resolução CONAMA no 3/1990. Segundo esta legislação, os padrões estabelecidos constituem um dos instrumentos de gestão da qualidade do ar, determinado como valor de concentração de um poluente específico na atmosfera, associado a um intervalo de tempo de exposição, para que o meio ambiente e a saúde da população sejam preservados em relação aos riscos de danos causados pela poluição atmosférica.

Os padrões nacionais de qualidade do ar são divididos em duas categorias:

I - padrões de qualidade do ar intermediários - PI: padrões estabelecidos como valores temporários a serem cumpridos em etapas; e

II - padrão de qualidade do ar final - PF: valores guia definidos pela Organização Mundial da Saúde - OMS em 2005;

A Resolução CONAMA no 491/2018 traz ainda:

"Art. 4ㅇ Os Padrões de Qualidade do Ar definidos nesta Resolução serão adotados sequencialmente, em quatro etapas.

$\S 1$ 10 A primeira etapa, que entra em vigor a partir da publicação desta Resolução, compreende os Padrões de Qualidade do Ar Intermediários PI-1.

$\S$ 2ㅇ Para os poluentes Monóxido de Carbono - CO, Partículas Totais em Suspensão - PTS e Chumbo - Pb será adotado o padrão de qualidade do ar final, a partir da publicação desta Resolução.

§ 30 Os Padrões de Qualidade do Ar Intermediários e Final - PI-2, PI-3 e PF serão adotados, cada um, de forma subsequente, levando em consideração os Planos de Controle de Emissões Atmosféricas e os Relatórios de Avaliação da Qualidade do Ar, elaborados pelos órgãos estaduais e distrital de meio ambiente, conforme os artigos 50 e 60, respectivamente.

$\S 4$ ㅇ Caso não seja possível à migração para o padrão subsequente, prevalece o padrão já adotado.

§ 5o Caberá ao órgão ambiental competente o estabelecimento de critérios aplicáveis ao licenciamento ambiental, observando o padrão de qualidade do ar adotado localmente."

Os parâmetros regulamentados pela legislação ambiental são os seguintes: partículas totais em suspensão (PTS), fumaça, partículas inaláveis $\left(\mathrm{MP}_{10}\right.$ e $\left.\mathrm{MP}_{2,5}\right)$, dióxido de enxofre $\left(\mathrm{SO}_{2}\right)$, monóxido de carbono $(\mathrm{CO})$, ozônio $\left(\mathrm{O}_{3}\right)$ e dióxido de nitrogênio $\left(\mathrm{NO}_{2}\right)$ (Tabela 1).

Em relação à contaminação do ar com metais tóxicos existe especificado no CONAMA 491/2018 valor limite estabelecido apenas para o chumbo $(\mathrm{Pb})$ sendo o PF correspondente a $0,5 \mu \mathrm{g} / \mathrm{m}^{3}$ identificado nas Partículas Totais em Suspensão (PTS) para a média aritmética anual. 
Tabela 1 - Padrões de qualidade do ar conforme CONAMA 491/2018

\begin{tabular}{|c|c|c|c|c|c|c|}
\hline \multirow[t]{2}{*}{ Poluente Atmosférico } & \multirow{2}{*}{$\begin{array}{l}\text { Período de } \\
\text { Referência }\end{array}$} & PI-1 & PI-2 & PI-3 & \multicolumn{2}{|c|}{ PF } \\
\hline & & $\mu \mathrm{g} / \mathrm{m}^{3}$ & $\mu \mathrm{g} / \mathrm{m}^{3}$ & $\mu \mathrm{g} / \mathrm{m}^{3}$ & $\mu \mathrm{g} / \mathrm{m}^{3}$ & ppm \\
\hline Material Particulado - & 24 horas & 120 & 100 & 75 & 50 & - \\
\hline $\mathrm{MP}_{10}$ & Anual $^{1}$ & 40 & 35 & 30 & 20 & - \\
\hline Material Particulado - & 24 horas & 60 & 50 & 37 & 25 & - \\
\hline $\mathrm{MP}_{2,5}$ & Anual $^{1}$ & 20 & 17 & 15 & 10 & - \\
\hline Dióxido de Enxofre - $\mathrm{SO}_{2}$ & 24 horas & 125 & 50 & 30 & 20 & - \\
\hline Dióxido de Nitrogênio - & 1 hora $^{2}$ & 260 & 240 & 220 & 200 & - \\
\hline $\mathrm{NO}_{2}$ & Anual $^{1}$ & 60 & 50 & 45 & 40 & - \\
\hline Ozônio - $\mathrm{O}_{3}$ & 8 horas $^{3}$ & - & $=$ & - & - & 9 \\
\hline Fumaça & 24 horas & 120 & 100 & 75 & 50 & - \\
\hline & Anual $^{1}$ & 40 & 35 & 30 & 20 & - \\
\hline $\begin{array}{l}\text { Monóxido de Carbono - } \\
\text { CO }\end{array}$ & 8 horas $^{3}$ & - & - & - & - & 9 \\
\hline Partículas Totais em & 24 horas & - & - & - & 240 & - \\
\hline Suspensão - PTS & Anual $^{4}$ & - & - & - & 80 & - \\
\hline Chumbo- $-\mathrm{Pb}^{5}$ & Anual $^{1}$ & - & - & - & 0,5 & - \\
\hline
\end{tabular}

1 - média aritmética anual

2 - média horária

3 - máxima média móvel obtida no dia

4 - média geométrica anual

5 - medido nas partículas totais em suspensão 
Tabela 2- Níveis de atenção, alerta e emergência conforme CONAMA 491/2018

\begin{tabular}{|c|c|c|c|c|c|c|}
\hline NÍVEL & $\begin{array}{l}\mathrm{SO}_{2} \\
\left(\mathrm{mg} / \mathrm{m}^{3}\right) \\
\text { (Média de 24h) }\end{array}$ & $\begin{array}{l}M P_{10}\left(\mathrm{mg} / \mathrm{m}^{3}\right) \\
\text { (Média de } 24 \mathrm{~h})\end{array}$ & $\begin{array}{l}M P_{2,5}\left(\mathrm{mg} / \mathrm{m}^{3}\right) \\
\text { (Média de } 24 \mathrm{~h})\end{array}$ & $\begin{array}{l}\text { CO (ppm) } \\
\text { (Médiamóvel } \\
\text { de } 8 \text { h) }\end{array}$ & $\begin{array}{l}\mathrm{O}_{3}\left(\mathrm{mg} / \mathrm{m}^{3}\right) \\
\text { (Médiamóvel de } \\
8 \mathrm{~h} \text { ) }\end{array}$ & $\begin{array}{l}\mathrm{NO}_{2}\left(\mathrm{mg} / \mathrm{m}^{3}\right) \\
\text { (Médiamóvel } \\
\text { de } 1 \mathrm{~h})\end{array}$ \\
\hline Atenção & 800 & 250 & 125 & 15 & 200 & 1130 \\
\hline Alerta & 1600 & 420 & 210 & 30 & 400 & 2260 \\
\hline Emergência & 2100 & 500 & 250 & 40 & 600 & 3000 \\
\hline
\end{tabular}

Tabela 3 - Parâmetros de qualidade do ar conforme CONAMA 491/2018

\begin{tabular}{llllllll} 
Qualidade & Índice & $\mathrm{MP}_{10}\left(\mu \mathrm{g} / \mathrm{m}^{3}\right)$ & $\mathrm{MP}_{2,5}\left(\mu \mathrm{g} / \mathrm{m}^{3}\right)$ & $\mathrm{O}_{3}\left(\mu g / \mathrm{m}^{3}\right)$ & $\mathrm{CO}(\mathrm{ppm})$ & $\mathrm{NO}_{2}\left(\mu \mathrm{g} / \mathrm{m}^{3}\right)$ & $\mathrm{SO}_{2}\left(\mu \mathrm{g} / \mathrm{m}^{3}\right)$ \\
& & $24 \mathrm{~h}$ & $24 \mathrm{~h}$ & $8 \mathrm{~h}$ & $8 \mathrm{~h}$ & $1 \mathrm{~h}$ & $24 \mathrm{~h}$ \\
N1 - Boa & $0-40$ & $0-50$ & $0-25$ & $0-100$ & $0-9$ & $0-200$ & $0-20$ \\
Não Boa & $>40$ & $\mathrm{MP}_{10}>50$ & $\mathrm{MP}_{2,5}>25$ & $\mathrm{O}_{3}>100$ & $\mathrm{CO}>9$ & $\mathrm{NO}_{2}>200$ & $\mathrm{SO}_{2}>20$ \\
\hline
\end{tabular}


Fregonese et al. (1997) informam que o referido metal pode causar vários efeitos indesejáveis, tais como: perturbação da biossíntese da hemoglobina, anemia, aumento da pressão sanguínea; danos aos rins; abortos; alterações no sistema nervoso; danos ao cérebro; diminuição da fertilidade do homem através de danos ao esperma; diminuição da aprendizagem em crianças; modificações no comportamento das crianças, como agressão, impulsividade e hipersensibilidade. O chumbo pode atingir o feto através da placenta da mãe, podendo causar sérios danos ao sistema nervoso e ao cérebro da criança.

A mesma resolução estabelece ainda os critérios para episódios agudos de poluição do ar. Ressalta-se que a declaração dos estados de Atenção, Alerta e Emergência (Tabela 2) requer, além dos níveis de concentração atingidos, a previsão de condições meteorológicas desfavoráveis à dispersão dos poluentes.

Em prosseguimento, é definido pelo CONAMA 491/2018 as condições para mensuração do Índice de Qualidade do Ar (IQAR) conforme apresentado na Tabela 3.

\section{MATERIAIS E MÉTODOS}

\section{ÁREA DE ESTUDO}

A área de estudo refere-se aos pontos de monitoramento de parâmetros físico-químidos da qualidade do ar do Instituto Estadual do Ambiente (INEA). Trata-se de rede automática composta por estações que realizam medições contínuas das concentrações dos poluentes dispersos no ar e dos parâmetros meteorológicos. Os poluentes monitorados são Partículas Totais em Suspensão (PTS), Partículas Inaláveis $\left(\mathrm{PM}_{10}\right)$, Dióxido de Nitrogênio $\left(\mathrm{NO}_{2}\right)$, Monóxido de Nitrogênio (NO), Óxidos de Nitrogênio $\left(\mathrm{NO}_{\mathrm{x}}\right)$ e Ozônio $\left(\mathrm{O}_{3}\right)$. Os parâmetros meteorológicos monitorados são direção e velocidade do vento, temperatura, umidade, radiação solar, pressão atmosférica e precipitação. Os dados obtidos são transmitidos em tempo real para órgãos fiscalizadores ambientais (APERAM, 2019).

A localização das estações que compõem essa rede de monitoramento é definida em concordância com a gestão pública dos municípios. Uma vez determinada à área de instalação de uma estação, realiza-se a seleção do local adequado para medição (microlocalização), bem como dos parâmetros de interesse a serem monitorados em cada estação. Esta localização segue ainda critérios mínimos de acordo com as características físicas de cada região, já que a área de abrangência da informação gerada dependerá de uma adequada localização do ponto de amostragem. As estações da rede automática se caracterizam pela capacidade de processar na forma de médias horárias, no próprio local e em tempo real, as medidas dos parâmetros de qualidade do ar. Estas médias são transmitidas para a central de telemetria e armazenadas em servidor de banco de dados dedicado, onde passam por processo de validação técnica periódica e, posteriormente, são disponibilizadas diariamente no endereço eletrônico dos setores fiscalizadores (APERAM, 2019). 
Nesse estudo, os dados foram coletados através dessa rede automática para a área urbana das cidades de Timóteo/MG e Coronel Fabriciano/MG (Figura 2) sendo localizados em Cecília Meireles, Escola Sementinha, Hospital Vital Brasil e Senac Vale do Aço sendo apresentadas as coordenadas na Tabela 4. Além disso, são apresentadas as variáveis físico-químicas monitoradas na Tabela 5 para o período de janeiro a dezembro de dois mil e dezenove.

Figura 2 - Localização das estações de monitoramento da qualidade do ar e metrologia

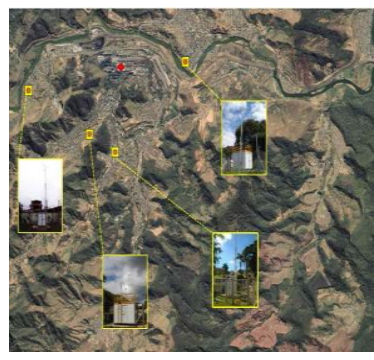

Fonte: APERAM (2019).

Tabela 4 - Coordenadas das estações de monitoramento

\begin{tabular}{llc}
\hline Localização das estações & & Coordenadas \\
Cecília Meireles & Latitude [] & $42^{\circ} 39^{\prime} 23^{\prime \prime}$ \\
Sementinha & $19^{\circ} 32^{\prime} 17^{\prime \prime}$ & $42^{\circ} 40^{\prime \prime} 16^{\prime \prime}$ \\
Hospital Vital Brasil & $19^{\circ} 32^{\prime} 59^{\prime \prime}$ & $42^{\circ} 38^{\prime} 33^{\prime \prime}$ \\
Senac vale do Aço & $19^{\circ} 31^{\prime} 49^{\prime \prime}$ & $42^{\circ} 37^{\prime} 38^{\prime \prime}$ \\
\hline
\end{tabular}

Fonte: APERAM (2019).

Tabela 5 - Estações e parâmetros de monitoramento

\begin{tabular}{llllllll} 
Estação & \multicolumn{7}{l}{ Parâmetros Físico-Químicos } \\
Cecília Meireles & $\mathrm{X}$ & $\mathrm{X}$ & $\mathrm{X}$ & $\mathrm{X}$ & $\mathrm{X}$ & $\mathrm{X}$ \\
Sementinha & $\mathrm{X}$ & $\mathrm{X}$ & & & & \\
Hospital Vital Brasil & $\mathrm{X}$ & $\mathrm{X}$ & & & \\
Senac Vale do Aço & $\mathrm{X}$ & $\mathrm{X}$ & & & \\
& & & & &
\end{tabular}

\section{Legenda:}

$\mathrm{MP}_{10}$ - Material Particulado com $\phi \leq 10 \mu \mathrm{m} ;$ PTS - Partículas Totais em Suspensão;

NO - Monóxido de Nitrogênio;

$\mathrm{NO}_{2}$ - Dióxido de Nitrogênio;

NOx - Óxidos de Nitrogênio;

$\mathrm{O}_{3}-$ Ozônio.

Fonte: APERAM (2019). 


\section{RESULTADOS E DISCUSSÃO}

O ar é um elemento essencial para a vida na Terra, desse modo, na mesma medida em são acentuados os transtornos decorrentes do incremento populacional em áreas urbanas, tornam-se progressivamente mais importantes o desenvolvimento dos programas de controle da poluição ambiental, de práticas contínuas de produção mais limpas e disseminação das informações sobre a qualidade do ar para a população (FEEMA, 2004).

A degradação da qualidade do ar pode ter conseqüências que extrapolam fronteiras, gerando tensões entre cidades e países. Os mecanismos associados a essa dinâmica decorem de um conjunto de fatores, tal como, taxa de emissões de poluentes associados aos sistemas de produção e modal rodoviário, características dessas substâncias, bem como a dispersão das mesmas na atmosfera e reações físico-químicas influenciadas pelas condições climáticas (FEEMA, 2008).

Em relação ao período de investigação não foram observados na região de estudo situações de risco para a população em relação aos níveis de atenção, alerta ou emergência estabelecidos no CONAMA 491/2018 para as emissões de $\mathrm{SO}_{2}, \mathrm{MP}_{10}, \mathrm{CO}, \mathrm{O}_{3}$ ou $\mathrm{NO}_{2}$ (Tabela 3).

Entretanto, na área de estudo identifica-se a existência da indústria siderúrgica que se apresenta como a fonte estacionária mais importante incrementando a concentração de diversos poluentes, sendo apontada como responsável por emissão antrópica contendo os precursores da chuva ácida, tal como, $\mathrm{SO}_{2}$ e $\mathrm{NO}_{2}$ sendo provenientes principalmente da queima de combustíveis fósseis. Reforçam-se, as precipitações pluviométricas com pH menor que 5,6 são formadas através das reações desses gases com o oxigênio e vapor d'água transformando-se em compostos ácidos, principalmente, sulfúrico e nítrico. Outro fator agravante pode ocorrer à deposição seca pela carrreação desses compostos na poeira ou fumaça (NOGUEIRA et al., 2019).

Em outro ângulo, segundo o inventário de fontes da Fundação Estadual do Meio Ambiente (FEAM), os veículos leves e pesados são responsáveis por grandes emissões de $\mathrm{NO}_{x}, \mathrm{CO}$ e $\mathrm{MP}_{10}$. Sendo importante relatar a ocorrência de reações secundárias, tal como, as do NOx, juntamente com outros poluentes, que reagem com a luz solar e formam o ozônio $\left(\mathrm{O}_{3}\right)$. Esse produto ao nível troposférico (camada baixa da atmosfera) onde se encontra a vida, apresenta características oxidantes, sendo nocivo ao sistema respiratório do homem e causa queimaduras nas folhas das plantas (FEAM, 2014). Destaca-se que o modal rodoviário é bastante explorado na região de estudo constituindo-se no principal mecanismo de transporte para o deslocamento de pessoas, cargas e produtos perigosos, desse modo, intensificando a emissão dessas substâncias através dessas fontes móveis contribuindo para deterioração da qualidade do ar (QUEIROZ et al, 2008).

$\mathrm{Na}$ região de estudo nos meses que compreendem o verão, nota-se uma preponderância de instabilidade atmosférica, sendo observadas chuvas que causam em diversas oportunidades transtornos à população. Além disso, essa precipitação pluviométrica pode contribuir significativamente para a qualidade do ar sendo observada classificação boa em todas as estações de amostragens em dezembro/2019 (Tabela 7). 
A melhora da qualidade do ar na estação chuvosa evidencia concordância com os achados de Freitas e Solci (2009) que identificaram a importância do incremento da pluviometria e condições metrológicas (ventos e instabilidade do ar) como fatores contributivos para redução/remoção de contaminantes $\left(\mathrm{MP}_{10}\right.$, $\mathrm{SO}_{\mathrm{x}}, \mathrm{NO}_{\mathrm{x}}$, etc.) dispersos no ar que são incorporados à água de chuva, desse modo, podendo alterar as condições físico-químicas dos corpos hídricos superficiais com incremento dos teores dos compostos químicos dissolvidos na coluna d'água (QUEIROZ, 2017) Além disso, o solo úmido evita a ressuspensão das partículas na atmosfera. Em outro ângulo, constatou-se que a qualidade do ar se apresentou não boa em todas as estações de amostragens em julho/2019 (Tabela 6) possivelmente influenciada por bio-disponibilidade do $\mathrm{MP}_{10}$, que tende a aumentar quando há redução da pluviosidade, conforme achados de Freitas e Solci (2009) e Válio (2015).

A degradação da qualidade do ar pode contribuir com eventos adversos à saúde, principalmente no que diz respeito aos agravos relacionados ao quadro respiratório. Carneseca et al. (2012) relatam que o incremento dos teores de material particulado respirável $(\varnothing \leq 10 \mu \mathrm{m})$, de modo geral, mostra relação com eventos adversos exigindo incremento do número de nebulizações realizadas através do Sistema Único de Saúde (SUS) para atendimento principalmente da população mais vulnerável, idosos e crianças.

Além disso, Nascimento (2012) identificou que o decaimento da qualidade do ar associado ao incremento dos teores de $\mathrm{PM}_{10}, \mathrm{SO}_{2}$ e $\mathrm{O}_{3}$ contribui para a incidência de Acidente Vascular Cerebral (AVC) preponderantemente entre a população com idade superior a cinqüenta anos. Esse tipo de sinistro corresponde ao entupimento ou rompimento dos vasos que levam sangue ao cérebro, provocando a paralisia da região afetado sendo o tratamento, de modo geral, oneroso e prolongando (OLIVEIRA et al., 2019).

Em outro ângulo, na estação seca também é observada a queda da temperatura do ar sendo considerada como um dos principais atributos ambientais relacionado com os agravos das doenças respiratórias (SOUZA et al, 2018). Pereira et al. (2011) reforçam que a variação brusca da temperatura ao longo do dia pode interferir no desempenho do corpo humano, desse modo, as emissões gasosas da siderurgia associada às condições ambientais podem ocasionar a diminuição da capacidade e da função pulmonar, notadamente, em condições de exposição crônica e prolongada.

Constatou-se nesse estudo que as condições meteorológicas influenciam a mistura vertical do ar, desse modo, as concentrações de $\mathrm{O}_{3}$ aumentam, conforme diminuem as condições de mistura. Porém, sabe-se que as concentrações de NOx aumentam conforme aumenta a estabilidade vertical da atmosfera, o que afeta diretamente as concentrações de $\mathrm{O}_{3}$. Chiquetto (2008) destaca que as concentrações de ozônio troposférico num determinado local são afetadas pela constituição atmosférica, e esta é notadamente modificada em grandes centros urbanos onde há grandes emissões de precursores devido às atividades antrópicas, tal como, a siderurgia existente na região de estudo. De modo geral, observou-se a predominância da condição boa para qualidade do ar (Tabela 6), entretanto, nas estações de amostragens em Coronel Fabriciano e Cachoeira do Vale (Tabela 6) a classificação não boa correspondeu ao total de $50 \%$ dos achados explicitando a necessidade do aperfeiçoamento das medidas de contenção do risco ambiental. 
Dentre essas, pontua-se quanto ao uso de coletores mecânicos, filtros eletrostáticos, filtros de manga, dessulfurização dos gases e redução catalítica seletiva para controle tecnológico da planta siderúrgica para maximizar a captação e destinação adequada dos poluentes produzidos no processo (SILVA NETO et al., 2002).

Tabela 6 - Classificação da qualidade do ar nas estações de amostragens

\begin{tabular}{ccccc} 
Estação/Perído & Cecília Meireles & Sementinha & $\begin{array}{c}\text { Hospital Vital } \\
\text { Brasil }\end{array}$ & $\begin{array}{c}\text { Senac Vale } \\
\text { do Aço }\end{array}$ \\
Janeiro & Boa & Boa & Não Boa & Não Boa \\
Fevereiro & Boa & Boa & Não Boa & Não Boa \\
Março & Boa & Boa & Não Boa & Não Boa \\
Abril & Boa & Boa & Boa & Boa \\
Maio & Boa & Boa & Não Boa & Boa \\
Junho & Boa & Boa & Não Boa & Boa \\
Julho & Não Boa & Não Boa & Não Boa & Não Boa \\
Agosto & Boa & Boa & Boa & Não Boa \\
Setembro & Boa & Boa & Boa & Boa \\
Outubro & Não Boa & Boa & Boa & Não Boa \\
Novembro & Não Boa & Boa & Boa & Boa \\
Dezembro & Boa & Boa & Boa & Boa \\
\hline
\end{tabular}

\section{CONCLUSÃO}

Esse estudo avaliou os efeitos da siderurgia na qualidade do ar nas cidades de Coronel Fabriciano e Timóteo, MG, Brasil sendo constatado que esse tipo de empreendimento através dos seus efluentes gasosos incrementando a carga dos poluentes $\mathrm{PTS}, \mathrm{MP}_{10}, \mathrm{SO}_{2}, \mathrm{CO}, \mathrm{NO}_{2}$ e $\mathrm{O}_{3}$ na região de estudo.

A análise dos resultados mostrou que as variáveis meteorológicas afetam as concentrações de poluentes atmosféricos e que os índices de qualidade do ar estão associados às mudanças dessas variáveis oportunizando a ocorrência de condições classificadas como "boa" e "não boa" na região de estudo

Observou-se que as condições metrológicas interferem significativamente na concentração de $\mathrm{PM}_{10}, \mathrm{SO}_{2}$ e $\mathrm{NO}_{2}$ presente na atmosfera, favorecendo ou não o incremento da poluição do ar, desse modo, identificou-se a relevância dos fatores ambientais para favorecer a ocorrência da classificação "boa" conforme CONAMA 491/2018. Desta maneira, infere-se que o incremento da velocidade do ar e volume de chuvas são fatores que contribuem positivamente para a melhora da qualidade do ar, na região de estudo, favorecendo a dispersão e diluição dos poluentes.

Finalizando-se, pondera-se quanto à relevância de intensificar as investigações visando à proposição de medidas mitigadoras direcionadas para a manutenção do bem-estar público. 


\title{
Ar pollution aspects: air quality analysis in Coronel Fabriciano and Timóteo, MG, Brazil
}

\begin{abstract}
Industrial processes, motor vehicles and fires are, among human activities, the main causes of the introduction of pollutants into the atmosphere. These substances can have harmful effects on human health, still being able to cause damage to flora, fauna and materials, therefore, the investigation of the contents of these chemical compounds dispersed in the air is of high socio-environmental importance. In this study, information about the steel industry, pollutants generated and effects on air quality in the Vale do Aço region are presented, specifically in the cities of Coronel Fabriciano and Timóteo, Minas Gerais, Brazil. The findings are secondary data from the monitoring carried out by Aperam South America and being compared to the legal standards established in CONAMA $491 / 2018$ which are strictly met by the enterprise. However, high values of Total Suspended Particles (TSP) and Inhalable Particles (IP) were found, characterizing the air quality as regular in some periods, notably in the dry season. In addition, it is reinforced that several studies show that even in concentrations below the legal limits, there is a probability of deleterious effects for the population exposed to contaminated air. Thus, it is pointed out as to the need to develop more effective actions to mitigate environmental disorders.
\end{abstract}

KEYWORDS: Steel. Air Quality. Mitigating Measures. 
ALMEIDA,T. I, (1999). A Poluição Atmosférica por Material Particulado na Mineração a Céu Aberto. Tese de Mestrado. São Paulo: Engenharia. Universidade de São Paulo. cross ref

ALMEIDA, G. P. ; BITTENCOURT, A. T. ; EVANGELISTA, M. S. ; VIEIRA-FILHO, M. ; Fornaro, A. . Characterization of aerosol chemical composition from urban pollution in Brazil and its possible impacts on the aerosol hygroscopicity and size distribution. Atmospheric environment, v. 202, p. 149-159, 2019.

ASSUNÇÃO, J. V. Poluição Atmosférica. In CASTELLANO, E. G., Desenvolvimento Sustentado: Problemas e Estratégias. São Paulo, Academia de Ciências do Estado de São Paulo, 1998.

CABRAL, S. D. ; MIRANDA, V. A. A. ; HADDAD, A. N. . Planejamento de transporte como instrumento de melhoria da qualidade do ar.. In: Speranza França da Mata; Sérgio Gavazza; Maria Cândida Moreira de Almeida; Rubenildo Pithon de Barros. (Org.). Educação ambiental: projetivas do século. 1ed.Rio de Janeiro: MZ Editora, v. , p. 20-25, 2001.

CARNESECA, C. E.; ACHCAR, A. J.; MARTINEZ, Z. E. Associação entre a poluição atmosférica por material particulado e contagens mensais de procedimentos de inalação e nebulização em Ribeirão Preto, São Paulo, Brasil. Cadernos de Saúde Pública, Rio de Janeiro, v.28, n.8, p.1591-8, 2012. crossref

CETESB - COMPANHIA DE TECNOLOGIA DE SANEAMENTO AMBIENTAL, Composição e qualidade do ar, 2010. Disponível: <http: \\ www.cetesb.sp.gov.br>, Acesso: 03/11/2019.

CHIQUETTO, J. B.. Padrões atmosféricos associados a concentrações de ozônio troposférico na região metropolitana de São Paulo. Tese (Doutorado em Geografia Física) - São Paulo: Universidade de São Paulo, 2008.

CONAMA 491, 2018 - Resolução no 491, de 19 de novembro de 2018 - Revoga a Resolução Conama no 03/1990 e os itens 2.2.1 e 2.3 da Resolução Conama no 05/1989.

DREHMER, L. R.C.; PAUCAR CASAS, W. J.; GOMES, H. M. . Parameters optimization of a vehicle suspension system using a particles warm optimization algorithm. Vehicle System Dynamics, v. 53, p. 449-474, 2015. crossref 
FEAM - FUNDAÇÃO ESTADUAL DO MEIO AMBIENTE. Plano de Controle de Poluição Veicular do Estado de Minas Gerais: FEAM, 2014.

FEEMA. Fundação Estadual de Engenharia do Meio AMBIENTE. Inventário de Fontes Emissoras de Poluentes Atmosféricos da Região Metropolitana do Rio de Janeiro. Rio de Janeiro - RJ, 2004.

FEEMA. Fundação Estadual de Engenharia do Meio AMBIENTE. Relatório Anual de Qualidade do Ar, 2008.

FONSECA, C. M.O.. Estado, Sociedade Civil e Políticas de Saúde na Europa (séc. $\mathrm{XIX}$ e XX) . Resenha do livro Health Institutions at the origin of the welfare systems in Europe. Organização Pilar Sanchez. História, Ciências, SaúdeManguinhos (Impresso), v. 18, p. 311-315, 2011. crossref

FREGONEZE, J. B. ; MARINHO, C. A. ; SOARES, T. J. ; CASTRO, L. ; SARMENTO, C. ; CUNHA, M. ; GONZALEZ, V. ; OLIVEIRA, P. ; NASCIMENTO, T. ; LUZ, C.P. ; SANTANA JR. P. ; De OLIVEIRA, I. ; DE CASTRO, E. . Lead (Pb2+) and cadmium (Cd2+) inhibit the dipsogenic action of central beta-adrenergic stimulaiton by isoproterenol.. Brazilian Journal of Medical and Biological Research, Brasil, v. 30, p. 419-423, 1997. crossref

FREITAS, A. de M.; SOLCl, M. C.. Caracterização do $\mathrm{MP}_{10}$ e $\mathrm{MP}_{2,5}$ e distribuição por tamanho de cloreto, nitrato e sulfato em atmosfera urbana e rural de Londrina. Química nova, v. 32, n. 7, p. 1750-1754, 2009. crossref

IEMA - INSTITUTO DE ENERGIA E MEIO AMBIENTE. 1으 Diagnóstico da rede de monitoramento da qualidade do ar no Brasil, 2014.

KRECL, P.; TARGINO, A. ; KETZEL, M. ; CIPOLI, Y. ; CHARRES, I. . Potential to reduce the concentrations of short-lived climate pollutants in traffi c environments: A case study in a medium-sizedcity in Brazil. Transportion research part D Transport and environment, v. 69, p. 51-65, 2019. crossref

LEANDRO, C. A. S.. Introdução a Siderurgia. 1. ed. São Paulo: ABM, v. 1. 428p ., 2007.

LEANDRO, C. A. S.; MOURAO, M. B. ; YOKOJI, A. ; MOLYNOWSKYI, A. ; TAKANO, C. ; QUITES, E. E. C. ; GENTILE, E. F.; SILVA, G. F. L. E. ; BOLOTA, J. R. ; GONZALVES, M. ; FACO, R. J. . Introdução a Siderurgia. 01. ed. São Paulo: Livros ABM,. v. 01. $428 p, 2007$. 
MACINTYRE, A. J. - Ventilação Industrial e o Controle da Poluição. ed. Guanabara, Rio de Janeiro, 1988. 403p. p. 4-5.

MANAHAN,S.E., Environmental Chemistry, 7 ed, New York, CRC Press LLC, 2000.

MEIRELES, R. C. DE ; TEIXEIRA, J. P. G. ; SOLAR, R. ; VASCONCELOS, B. N. F. ; FERNANDES, R. B. A. ; LOPES, L. E. . Soil attributes drive nest-site selection by the campo miner Geositta poeciloptera. PLoS One, v. 13, p. e0192185, 2018. crossref

MUNDO EDUCAÇÃO, Editora Abril, Camadas da atmosfera, 2020.

Disponível:<https://mundoeducacao.bol.uol.com.br//>, Acesso: 11/03/2020.

NAKAGAWA, L.; COMARÚ, F.; MORANTE, F. . Estudo dos efeitos na qualidade do ar e na saúde humana do funcionamento de usinas termoelétricas em regiões intensamente urbanizadas: o caso da UTE Piratininga - SP. Revista Brasileira de Energia, v. 16, p. 49-61, 2010.

NASCIMENTO, L. F. C. Poluentes ambientais e internações devido a acidente vasculoencéfalico. Cadernos de Saúde Pública, Rio de Janeiro, v.28, n.7, p.131924, 2012.

NOGUEIRA, T.; DOMINUTTI, P. A. ; VIEIRA-FILHO, M. S. ; FORNARO,A. ; ANDRADE, M. F. . EvaluatingAtmosphericPollutantsfromUrbanBusesunder Real-World Conditions: ImplicationsoftheMainPublicTransportMode in São Paulo, Brazil. Atmosphere, v. 10, p. 1-20, 2019. crossref

OLSZEWER,E.. Clínica ortomolecular. 2ª ed. São Paulo, Roca: 2008.

OLIVEIRA, A. A. B., Inventário das emissões atmosféricas na indústria siderúrgica, Trabalho de Conclusão de Curso,Universidade Federal do Rio de Janeiro, Escola Politécnica, Curso de Engenharia Metalúrgica, 2014.

OLIVEIRA, D.C.; MELO, L. P.; SILVA JÚNIOR, R.A.; CAVALCANTI, F. A. C. , CAMPOS, T. F. . Dependência funcional e a necessidade de fisioterapia na fase aguda do acidente vascular cerebral. Fisioterapia \& Saúde Funcional, v. 6, p. 43-50, 2019.

PAIVA, F. S. De; STRALEN, C. J. V.; COSTA, P. H. A. da. Participacão social e saúde no Brasil: revisão sistemática sobre o tema. Ciência e Saúde Coletiva (Impresso), v. 19, p. $487-498,2014$. crossref 
PATTINSON,W.; TARGINO, A. C.; GIBSON, M. D.; KRECL, P.; CIPOLI, Y. ; SÁ,V..Quantifying variation in occupational air pollution exposure within a small metropolitan region of Brazil. Atmosferic Environment, v. 181, p. 1-154, 2018.

crossref

PEREIRA, V.S.; ROSA, A. M.; HACON, S. S.; CASTRO, H.A. ; IGNOTTI, E. . Análise dos atendimentos ambulatoriais por doenças respiratórias no Município de Alta Floresta, Mato Grosso, Amazônia brasileira. Epidemiologia e Serviços de Saúde, v. 20, p. 393-400, 2011. crossref

SILVA NETO, O. G.; AGUIAR, M. L. ; COURY, J. R. . Filtração de Gases em Filtro de Manga: Estudo da Porosidade. Revista Universidade Rural. Série Ciências Exatas e da Terra, v. 21, p. 187-195, 2002.

SILVEIRA, A. R. ; BRANTE, A. R. S. D. ; STRALEN, C.J.V . Práticas discursivas na participação social e saúde mental. Saúde em Debate, v. 38, p. 783-793, 2014. crossref

SOUZA, E. C. DE O.; SANTOS, E. S. DOS; ROSA, A. M.; BOTELHO, C.. Socioeconomic factors and risk for hospitalisation due to asthma in children in the municipalities of Mato Grosso State, Brazil. Ciência \& Saúde Coletiva, v. 23, p. 2523-2532, 2018. crossref

SOUZA, J. P. M. de. Epistemologia da Educação Física : análise da produção científica do Programa de Pós-graduação da Faculdade da Educação Física da UNICAMP (1991-2008). Tese (Doutorado) - Faculdade de Educação. Universidade Estadual de Campinas (UNICAMP). (06/57093-7), 2011.

SPAGNOL, C.; BANCZEK, E. DO P.; COSTA, I. ; CUNHA, M. T. ; GALLINA, A. L. ; TUSSOLINI, M. ; RODRIGUES, P. R. P. . Corrosion characterization of phosphated carbon steel treated with benzotriazole. Anti-Corrosion Methods and Materials, v. 62 , p. $379-387,2015$. cross ref

WHO.The world healthreport, 2002.Reducingrisks, promotinghealthylife: WHO Geneva, Switzerland; 2002.

QUEIROZ, M.T.A. Avaliação da qualidade da água da sub-bacia do Rio Piracicaba e da sua área de influência no reservatório da usina hidroelétrica de Sá Carvalho, Antônio Dias, MG, Brasil, Tese (Doutorado em Saneamento, Meio Ambiente e Recursos Hídricos), UFMG, Brasil, 2017.

QUEIROZ, M. T. A.; SILVA, A. R. S.; FLORÊNCIO, I. de S. F.; SILVA, R. R.; PÉRPETUO, T. M. C.. Acidentes no Transporte de Cargas/Produtos Perigosos no Colar 
Metropolitano do Vale do Aço, Minas Gerais. In: Anais, V Simpósio de Excelência em Gestão e Tecnologia, 2008, Resende - RJ. V SEGet, 2008.

VÁLIO, V. M.. Análise do material particulado atmosférico em uma região de São Carlos-SP. 2015. 127 f. Dissertação (Mestrado) - Curso de Engenharia Hidráulica e Saneamento, Universidade de São Paulo, São Carlos, 2015. Disponível em: http://www.teses.usp.br/teses/disponiveis/18/18138/tde13082015-144101/ptbr.php. Acesso em: 02 mar. 2020.

QUEIROZ, M.T.A. et al. Aspectos da poluição atmosférica: análise da qualidade do ar em Coronel Fabriciano e Ipatinga, MG, Brasil. R. Gest. Industr., Ponta Grossa, v. 16, n. 1, p. 204-223, Jan./Mar. 2020. Disponível em: https://periodicos.utfpr.edu.br/revistagi.

Correspondência:

Marluce Teixeira Andrade Queiroz

Centro Universitário do Leste de Minas Gerais (Unileste), Coronel Fabriciano, MG, Brasil.

Direito autoral: Este artigo está licenciado sob os termos da Licença Creative Commons-Atribuição 4.0 Internacional. 